\title{
ETHICAL ASPECTS INVOLVING THE USE OF INFORMATION TECHNOLOGY IN NEW SURGICAL APLICATIONS: TELESURGERY AND SURGICAL TELEMENTORING
}

\author{
Fernando Fuertes-Guiró ${ }^{1}$, Eduardo Viteri Velasco ${ }^{2}$
}

\begin{abstract}
The surgical telementoring is a technology that involves surgical procedures guided by an expert or mentor, performed by other surgeons from a distance, using information and knowledge technologies. This therapeutic innovation has generated new opportunities to improve the surgical attention and the training of the surgeons. However, their ethical implications should be analyzed to clarify their use, to check the patient's safety and eliminate uncertainties. The characteristics of surgical telementoring generate specific challenges and ethical dilemmas that must be identified, analyzed and solved. In this paper the ethical challenges and dilemmas of surgical telementoring identified and analyzed cover multiple aspects such as patient safety, privacy and vulnerability, the surgeon-mentor-patient relationship and informed consent, professional responsibility, cost-effectiveness analysis and Solidarity and social justice regarding the use of healthcare resources, the systematic approach to validation of the proposed new technology and conflicts of interest. Surgical telementoring potentially improves patient healing and surgeon education. It will have a rapid evolution in the next years. This rapid growth should not be anticipated to the solid implantation of ethical guarantees for its use due to the particular characteristics that this technology has in the field of telemedicine.
\end{abstract}

Key words: surgical telementoring, telesurgery, ethical analysis

\begin{abstract}
Aspectos éticos relacionados con el uso de información tecnológica en nuevas aplicaciones quirúrgicas: tele-cirugía y tele-tutoría

Resumen: La tele-tutoría en cirugía es una tecnología que incluye procedimientos quirúrgicos guiados por un experto o tutor, realizado por otros cirujanos a distancia usando tecnologías de información y conocimiento. Esta innovación terapéutica ha generado nuevas oportunidades para mejorar la práctica de cirugía y la formación de los cirujanos. Sin embargo, debería analizarse sus implicaciones éticas para clarificar su uso, comprobar la seguridad del paciente y eliminar incertidumbres. Las características de la tele-tutoría en cirugía generan desafíos específicos y dilemas éticos que deben identificarse, analizarse y resolverse. En este artículo se identifican y analizan múltiples aspectos en cuanto a desafíos éticos y dilemas de tele-tutoría en cirugía, tales como seguridad del paciente, privacidad y vulnerabilidad, la relación cirujano-tutor-paciente y el consentimiento informado, la responsabilidad profesional, análisis de costo-efectividad, solidaridad y justicia social respecto del uso de recursos en el cuidado de la salud, aproximación sistemática para la validación de la nueva tecnología propuesta y los conflictos de interés. La tele-tutoría en cirugía mejora potencialmente la sanación del paciente y la educación del cirujano. Su rápido crecimiento no debería anticiparse a la implantación sólida de garantías éticas para su uso, debido a las características particulares que tiene en el campo de la tele-medicina.
\end{abstract}

Palabras clave: tele-tutoría en cirugía, tele-cirugía, análisis ético

Aspectos éticos envolvendo o uso de tecnologia da informação em novas aplicaçôes cirúrgicas: telescirurgia e telemonitoria cirúrgica

Resumo: A cirurgia teleguiada é uma tecnologia que envolve procedimentos cirúrgicos, guiados por um especialista ou mentor, executados por outros cirurgióes à distância, usando tecnologias da informação e do conhecimento. Esta inovação terapêutica tem gerado novas oportunidades para melhorar a atenção cirúrgica e a formação dos cirurgiôes. No entanto, suas implicaçôes éticas devem ser analisadas para esclarecer seu uso, para verificar a segurança do paciente e eliminar as incertezas. As características da cirurgia teleguiada geram desafios específicos e dilemas éticos que devem ser identificados, analisados e resolvidos. Neste artigo os desafios éticos e dilemas da cirurgia teleguiada identificados e analisados vislumbram vários aspectos como a segurança do paciente, sua privacidade e vulnerabilidade, o relacionamento paciente-cirurgiáo-mentor e consentimento informado, responsabilidade profissional, análise custo-eficácia e solidariedade e justiça social em relação ao uso dos recursos de saúde, a abordagem sistemática para validação da tecnologia nova proposta e conflitos de interesse. A cirurgia teleguiada potencialmente melhora o atendimento do paciente e o ensino do cirurgião. Seu rápido crescimento não deve ser antecipado para a implantação contínua de garantias éticas para seu uso devido as características particulares que esta tecnologia tem no campo da telemedicina.

Palavras-chave: cirurgia teleguiada, análise ética

${ }^{1}$ Faculty of Medicine and Health Sciences, Universitat Internacional de Catalunya, Barcelona. Spain. Department of Surgery, Quirón Salud University Hospitals, Barcelona, Spain

Correspondence: fernandofuer@gmail.com

${ }^{2}$ Department of Surgery, Quirón Salud University Hospitals, Barcelona. Spain 


\section{Introduction}

The definition of surgical ethics has been constantly evolving since its inception in the eighteenth century by Gregory and Percival(1). While it was initially a response to the need to protect patients, provide more safety in medical procedures and maintain confidence in surgeons, in the following centuries it was developed based on advances in the field of anesthesia, antisepsis and the development of new methodologies, techniques and surgical procedures. The era of transplantation and the consolidation of mini-invasive surgery in the twentieth century and surgical robotics and information and knowledge technologies (ICTs) applied to surgery in the twenty-first century are creating new previously unknown areas of surgical ethics.

The doctor-patient relationship is the central feature of clinical ethics, and thus also of surgery. This relationship must be the starting point and the cornerstone of surgical ethics. However, there is some distance between surgical ethics regarding the doctor-patient relationship and medical ethics according to the differences defined by Miles Little(2): the surgeon's power to rescue patients, the special surgeon-patient proximity in the operating theatre, tests that patients undergo in the pre-, peri- and post-surgery periods, and the physical-emotional consequences of surgical treatment, as well as the patient's desire to be treated by an experienced surgeon.

The general criterion for surgical progress has always been reduced morbidity and mortality in terms of complications or death. When evaluating surgical innovations, other variables that are taken into account are the disease-free period, the recurrence rate, and shorter hospitalization times. However, in recent years, the values for the patient in terms of subjective benefits, such as the aesthetic result, have been added to these variables. When new surgical procedures are proposed, it is therefore necessary to assess the true progress that their implementation entails(3).

\section{Telemedicine, Telementoring and Telesur- gery}

We consider telemedicine to be procedures that use medical information that is exchanged from one physical location to another using ICTs in order to improve the patient's state of health(4). For part of the scientific community, this term is too specific and they prefer to call it telehealth or telecare (5). As this major field of applied medicine has developed, various ways of exchanging this medical information have emerged, and have been called by various names, such as teleconferencing, telemonitoring, telepresence, interoperability, teleconsultation and telementoring(6). We will consider the last two.

The Society of American Gastrointestinal and Endoscopic Surgeons (SAGES) defines telementoring(7) as an relationship facilitated by ICTs, in which an expert (mentor) provides advice to another less experienced professional (mentoring) from a remote location. It is different from teleconsultation, in which the professional expert uses store and forward or videoconferencing to provide information to a professional user.

Telementoring is based on four premises: 1 . The establishment of a strong professional relationship between mentor and mentee, in which the former is aware of the mentee's abilities, limitations and way of working; 2 . The mentee must be able to manage the patient's illness, as if the mentor were not present, despite using a different surgical technique; 3 . It is an educational process in which mentor and mentee have had to prepare previously for the experience; 4 . The advice must be comprehensive and sufficient, so that the mentee can work safely and the technological support therefore must be extensive (including telestration).

Telementoring is the result of a twofold need (educating and providing care) at a time in the history of medicine when technological progress is so rapid that outside the hospital environment they have a well developed infrastructure which other professionals are unable to assimilate. Since its inception, telementoring has been an almost exclusively surgical application, and specifically for mini-invasive surgery, with its main applications being correction of the deficit in the learning curve of new surgical techniques for surgeons in rural hospitals(8) and counseling in special situations, such as hospitals in war zones(9). Hospitals 
providing this service(10) with surgical robots and joint development projects have appeared in recent years(11). Several review studies on the application of telementoring in mini-invasive surgery have been published, and concluded that it is a safe and effective procedure that is comparable to face-to-face mentoring(12-17).

However, surgical telementoring is not without its disadvantages. It is a procedure that relies on an adequate telecommunications infrastructure, and any failure would leave the mentee without expert assistance with consequences for the patient. In addition, the legal requirements and the authorization to practice vary from one country to another. Furthermore, the doctor-patient relationship is altered by including a third person whose role in this new interpersonal relationship is to be defined. Logistical changes, the development of a new business, the sharing of responsibilities and the inherent legal aspects (regulations, licenses, competence and suitability of surgeons, among others) must also be considered. Finally, other issues that arise with the use of surgical telementoring are new responsibilities for professionals, the patient's increased vulnerability, the need for a new informed consent, new intellectual rights, jurisdictional problems depending on the type of health system in which the telementoring takes place (public health, i.e. copayment, or private health, i.e. reimbursement), protection and safety, the right of the patient to access this new technology, and the need to establish new protocols and clinical guidelines.

The latest new step in this process of surgical mentoring using ICT is telementoring telesurgery. In this new technology, the mentor is the surgeon who performs the surgical operation at a distance, and only requires one or two surgeons to supervise the operation. The development of this new technique has been dazzling, with the arrival of robotic surgery (robotic tele-surgical system), which was first proposed and documented in 2005(18) with the da Vinci system. With this system, the mentor surgeon personally directs the movements of the robot in the operating room, performing the operation, or part of the operation, when the surgeons present in the operating theatre have difficulties.
Telementoring is an increasingly consolidated procedure in surgical practice, and needs a legal and ethical architecture for its correct development and application.

\section{Telemedicine, ethics and ethical guidelines}

Telemedicine has been used by the international medical community for more than 60 years, but the ethical debates around it emerged later. There have been three generations of telemedicine. The first generation (which began in the United States and Canada in the 1950s and 1960s, aimed to demonstrate its technological viability by extending scarce medical resources over long distances using audio and video media and the telephone. The second generation began to emerge in the late 1980 s, with the miniaturization and portability of information technology, the emergence of the Internet, multimedia browsers and e-mail. Finally the third generation began in the late 1990s, and includes today's telemedicine. However, unlike previous generations, the third generation is being controlled by government legislation with the establishment of the first ethical guidelines for telemedicine.

With this passage of time, the feasibility, safety and clinical advantages of telemedicine have been confirmed and today it is recognized as one of many tools for improving patients' healthcare. Indeed, many patients have benefited from telemedicine when they had no other means of accessing health systems. In addition, the patients themselves are satisfied with ICTs because they provide them with uninterrupted care. For professionals, telemedicine has had many advantages: the development of protocols for the immediate treatment of emerging pathologies, the creation of systems to obtain information quickly, a means to receive specialized and expert advice, support for the follow-up of chronic pathologies, treatment adherence systems, and monitoring patients.

However, from the economic point of view, there is no unanimity regarding the cost-effectiveness of this new technology, partly due to the few studies that analyze the necessary variables(19).

The application of telemedicine should be guided by the same ethical principles upon which medi- 
cine was based before the use of this new technology. However, the particular technical characteristics of this medical innovation create a series of ethical issues that have begun to arise only after years of application. These issues include the impact on the patient-physician relationship, including the loss of direct professional-patient physical contact with potential depersonalization; the new burden of information that must be placed on the patients regarding the technology used, in addition to the information that is normally provided to them about their pathology; new challenges related to privacy and confidentiality; possible inequality in the distribution of the benefits of telemedicine services; technology as an additional burden for patients with chronic and terminal illnesses; the impact of replacing real visits with virtual visits, and the risk of exploitation when using new and expensive technology.

Telemedicine has developed as such a rapid rate that numerous variants in its application have appeared in only a few years. Many of them have not been subjected to rigorous ethical studies and are applied based on general principles based mostly on common sense. In some cases, ethics committees or governments act as filters for the approval of these new types of telemedicine (20). On other occasions, the scientific community follows all the established steps to prove its effectiveness and security before announcing a new technology based on ICT(21).

However, there are potential ethical dilemmas posed by applications of telemedicine in which the value of individuals able to pursue their own interests in their own way contradicts the value of society's efforts to reduce harm and to use public resources more fairly and efficiently. Scientific societies and professional associations have begun to adopt ethical guidelines for the application of telemedicine for this reason.

The Standing Committee of European Doctors (CPME) approved the first ethical guidelines on telemedicine in 1997 and confirmed them in 2002. This guide defined the basic principles for authorization and professional competence for their application, the doctor-patient relationship, the responsibility of the physician, and established quality and safety criteria and stipulated the rules for preserving the confidentiality of patients' data(22).

Later, in 2007, the General Assembly of the World Medical Association (WMA) established its basic ethical principles for the use of telemedicine, which consisted of three aspects: the physicianpatient relationship and confidentiality, establishment of professional responsibilities and quality of medical care(23). Recently, in 2016, the American Medical Association (AMA) established its ethical guidelines for the use of telemedicine (24). These guidelines are based on an awareness that the multiple and novel applications of telemedicine have their limitations. These ethical principles oblige physicians who use them to make a series of commitments: to inform patients of the limitations of telemedicine, to warn patients how to plan the monitoring of their diseases; to advise patients to go to their primary healthcare doctors to let them know that they are involved in a telemedicine process; and to promote initiatives to universalize the use of telemedicine to those who can benefit from it. All these guidelines and minimum ethical guidelines approved by these medical associations are an important framework for action in telemedicine. However if we consider all technologies, both new and old, encompassing telemedicine, there are particular dilemmas and challenges for each one. These particular issues must be identified and resolved to be able to work under optimum conditions. Surgical telementoring is a technology that uses ICTs requiring an in-depth analysis of their ethical challenges and dilemmas, to which a solution must be provided. The rapid evolution and implementation of surgical telementoring also justifies this analysis.

\section{Dicussion}

The Belmont Report of 1979(25) defined the four basic ethical principles to take into account in medical practice: beneficence, non-maleficence, respect for the patient's autonomy and justice. The principles of truthfulness, integrity, honesty and respect for the rights of patients were subsequently added to the previous ones. The first principle means that any medical act is intended to benefit the patient. The second principle states that no medical act must cause harm to the patient. The third assumes that the patient is able to 
make decisions about medical acts that affect his or her health and the surgical team must respect them. For this, two conditions are required of the patient: they must make these decisions without external interference (with total freedom) and the patient must be psychophysically fit to take them (intentionality). The fourth ethical principle refers to the fairness, adequacy and fair treatment that must be applied to the patient by the professionals.

When we want to implement a telementoring program, these principles must be respected in order to make medical practice an act of morality and respect towards patients. However, there are 10 issues, including dilemmas and challenges, that we find when we want to apply this surgical telementoring programme (which are also applicable to robotic telesurgery) and which could violate these ethical principles(26).

Safety of telementoring in terms of ICT for the live exchange of information; the interrelation and degree of training of the surgeons (mentor and surgeons operating): parameters of surgical suitability.

When applying a surgical innovation, concern for patient safety should be the first need to be addressed. This involves complying with the ethical principles of charity and not malfeasance. When a surgical novelty is applied, there is very often an increase in morbidity and mortality - in comparison with the applied standard - because it is related to the learning curve. However in telementoring, the aim is to reduce morbidity and mortality related to certain operations because of the lack of training and experience of the surgeons involved. Consequently, the safety of telementoring refers to the safety of ICT in terms of the live exchange of information, safety in the personal interrelations and the degree of training of the surgeons (the mentor and surgeons operating) to carry out telementoring and the safety security of the experience of the surgeons in the pathology to be operated on.

Regarding the first point, numerous studies $(27,28)$ have demonstrated the safety and feasibility of surgical telementoring, which has complication rates lower than $5 \%$, similar to the same surgery without telementoring(29). Howe- ver, there are still some issues to be resolved regarding the ideal method for videoconferencing, resolution and latency requirements, and the ability to adapt telementoring to emerging technology. We will act according to ethical principles if we ensure a correct exchange of information between the mentor and the operating surgeon. To achieve this, the following minimum requirements must be met: the use of cameras that combine high resolution and high resolution; the mentor surgeon's ability to zoom directly; the existence of an additional interactive communication system as well as voice and image, such as telestration or laser pointing. The connection delay should also be less than $250 \mathrm{~ms}$, although numbers of up to 700 can be used in telementoring without any problems. A delay exceeding $500 \mathrm{~ms}$ has been documented as being potentially harmful(30).

When a hospital decides to undertake a surgical telementoring procedure, the suitability of the mentor surgeon's relationship with the acting surgeons must be assured. The professionals must also have acquired sufficient telementoring skills and knowledge. Like all professionals, the participants in the telementoring should make sure of the benefit rather than malfeasance of their actions towards the patient. Pellegrini(31) defined three phases for the incorporation of a new technology in surgical practice: familiarization with the cognitive aspects of the new technology, acquisition of the necessary psychomotor skills and evaluation of the training acquired (based on the minimum required). Surgeons who participate in a telementoring operation must have met all three requirements. This training must be accredited by obtaining a training certificate for both the mentor and the acting surgeons. Some professional societies already demand it(32). Furthermore, the professionals involved in this procedure to have a mutual understanding of the way each other works in the operating room, their degree of consolidation of skills, and their surgical experience. Pre-telementoring and on-site verification (in the operating room) of all these conditions is therefore required: the mentor must play a coordinating and supervising role in this prior phase, and must pay particular attention to ascertaining the acting surgeon's learning curve for the operations to be mentored. Some authors(33) even consider it ne- 
cessary for the mentor to also participate in the patient's pre and postoperative periods of care. This involvement by the mentor should consist of discussion of the clinical cases to be operated on to assess the surgical indication, the suitability of telementoring, surgical planning, the suitability of the instruments and technology and the management of possible complications. In the postoperative period, the mentor must issue a report specifying the how the operation took place in terms of the telementoring aspects, which should be part of the record of the operation and therefore of the patient's medical history. The existence of this document will preserve the ethical principle of patient autonomy, as it will provide information for future decisions related to their health.

Finally, the hospital and professional societies must ascertain the general professional experience of the surgeons who will be involved in the operations with telementoring. A precondition for participation is that the acting surgeons must be at an intermediate stage in their learning curve of the pathologies that they want to operate on, and for the mentor to have completed their learning curve and to have already mentored --these pathologies in the operating theatre and online. Official training certificates for mentoring ICT operations must be issued(34).

\section{A new patient-surgeon relationship. Challenges of telementoring}

The doctor-patient relationship is the cornerstone of medical practice and therefore of medical ethics. A good surgeon-patient relationship involves openness, trust, and good communication so that surgeons and patients work in the same direction, based on the patient's ethical principles of beneficence, non-maleficence and autonomy. Compared to medicine without ICT barriers, telemedicine suffers from a lack of communication between those involved in medical procedure. This can lead to dehumanization by reducing the patient to an object(35). There are few studies that analyze this problem in detail, but all of them point out that with telemedicine patients have a high degree of satisfaction with the results obtained(36). For this reason, the ethical guidelines approved by international medical institutions(23-25) highlight this problem and all agree that telemedicine should be used primarily in situations where the physician cannot be physically present in a safe and acceptable time; and once its use has been decided upon, the doctor-patient relationship should be based on mutual trust and respect. In addition, these studies conclude that telemedicine should only be used in cases where there is a previous personal relationship between the patient and the physician organizing or providing the telemedicine service.

However these ethical principles vary when it comes to establishing the ethical criteria for the application of telementoring, and create a new challenge. In telementoring there is a remote surgeon, the mentor, who is involved in the process, which changes the traditional surgeon-patient relationship and leads to a change in professional collaboration. Although there is no unanimity regarding the definition of the role of the mentor in this new doctor-patient relationship, the truth is that the mentor is usually assigned a secondary role in the process (37). Nevertheless, the mentor should be part of a new three-way patient doctorpatient relationship, because his commitment to the patient's ethical principles of beneficence, non-maleficence and autonomy must also be maintained and respected in the same way as the operating surgeons. In practice, it means that the patient must meet and get to know the mentor and the operating surgeons simultaneously before the operation and jointly decide on the pathology, therapeutic options, potential complications and their management. However, it must be said that many times this does not happen.

\section{Determination of professional responsibility}

In general terms, medical professional liability is understood to mean the duty of doctors to make amends for and make good the consequences of voluntary and even involuntary acts, omissions and errors, committed in the exercise of their profession, and within certain limits. Although the term may refer to ethical-moral, labor, legal, civil and criminal aspects, in practice we will consider ethical-moral issues. Unlike traditional medicine, in telemedicine professional liability has two branches: the operating physician and the administrator of the ICT system that acts as an interface. In the case of telementoring, in addi- 
tion to the two areas mentioned above, the professional responsibility that has to be defined is that of the mentor, which is also a twofold ethical challenge: responsibility towards the rest of the surgical team, and responsibility that arises when the mentor is an a different country to where the operation is being performed.

The professional responsibility of the mentor within the surgical team can only be demanded due to the competences that have been assigned to him in the role defined for him in the pre-, intra- and postoperative periods. His sole responsibility in the preoperative period will be limited to the supervision and evaluation of the surgical team that will operate on the patient, evaluation of the ICT system to be used and the suitability of the patient and their pathology for the application of telementoring. In the intraoperative period, his professional responsibility is related to mentoring the operating surgeons using the ICT system applied in good working order and it will be necessary to record the entire surgical operation to that end. The mentor will be responsible for all decisions made with the rest of the surgical team in the three operative periods (need for conversion, hospital discharge, management of complications, etc.). It is therefore understood that if a failure in the telecommunications system occurs, the sole responsibility for continuing the operation will fall to the surgeons who are in the operating room.

Surgical telementoring currently takes place within the borders of a single country, and professionals in other countries are unable to participate, mainly due to problems of assignment of professional responsibility and the legal framework(38). The rapid development of surgical telementoring will enable the mentor the operating room where the patient is operated to be located in different countries. The mentor carries out a professional task on a patient requiring their accreditation as being able to practice the profession in the country where the operating room is located. The dilemma is whether this accreditation has to be an official authorization (from a college of doctors, ministry, etc.) equivalent to the one required for all professionals in that country, or whether only a specific and temporary authorization that requires official verification of the mentor's training is necessary. In either case, the ethical principles of the patient may be preserved, although adequate legal cover will be required. The issues surrounding professional liability coverage and healthcare during the flight that airlines arrange for their passengers may be an example to follow for surgical telementoring between several countries.

\section{Privacy of the patient}

The confidentiality of the information collected in a telementoring process means the patient's privacy is preserved - or their image is protected. It is based on a relationship of trust between the surgical team and the patient, and represents the limited use of medical information available to the professionals. In ethical terms it is based on the principles of justice (the common good is preserved), of charity and not of maleficence. This privacy has two exceptions: when it negatively affects the public welfare, and the safety of others.

In surgical telementoring, privacy has two branches: the branch involving the medical procedure and the one derived from the transmission of the patient's information using the ICT during the operation. To do this, it will be necessary to use a secure network system and specifically, a virtual private network (VPN) with a defined encryption system (e.g. a 256-bit AES, or advanced encryptation standard) (39).

\section{Need for new informed consent}

Informed consent in surgical telementoring must be accepted autonomously after a process that includes full information, develops adequate understanding and is voluntarily, freely and conscientiously approved. The ethical principle of patient autonomy must be preserved. Informed consent in surgical telementoring has some specific characteristics that constitute real ethical challenges and dilemmas:

1. A new figure emerges in operations carried out with telementoring, i.e. the mentor. The patient must therefore be informed about this as part of the operation to be carried out and the fact that the intervention will be mentored must be included, as well as the name of the mentor. It is ethically reasonable for the patient to meet the 
mentor before consenting to the operation, and for the informed consent process to involve the operating surgeons, the mentor surgeon and the patient.

2. There should be no application of the ethical principle of therapeutic privilege or the omission of certain information to the patient, which if known would make him/her take a decision against his or her interests according to the surgeons. It is necessary to take into account that the mentoring benefits the surgical team, which due to a lack of experience can thereby operate more safely, and therefore also benefits the patient. An explanation she consequently be given for all the reasons that justify the patient's operation being mentored.

3. The patient should have the opportunity to be informed of the risks of telementoring with their complications, benefits and alternatives, in addition to those of the operation. Since this is a surgical innovation, there are as yet not enough publications to ascertain all the risks that surgical telementoring entails. To resolve this dilemma, the mentor surgeon should to explain the limits of current knowledge of telementoring and the uncertainty involved in applying innovative technology to the patient. This explanation will be a challenge for the mentor - i.e. explaining it properly - and for the patient - understanding it correctly. The opportunity possibility to make the operation one involving open surgery should be mentioned without the mentor's participation.

4. As it is a surgical innovation, we can find biases when the surgeon interacts with the patient and the surgeons interact with the companies providing the telementoring service. The surgeon's enthusiasm for new surgical technology can therefore influence the patient's decision-making. Meanwhile, the surgeon and the medical center may be enthusiastic about the information offered by the company providing the service. All this may lead to bias in the information provided to the patient and the patient may make a decision without adequately considering the risks and benefits and alternatives to telementoring (40). Two solutions have been proposed to resolve this dilemma. Paternalism and persuasion should be avoided, preventing the conflict arising from the contradiction between the ethical principles of autonomy and charity. Furthermore, the informed consent for surgical telementoring should encompass an information process, a process of interpretation and a deliberation process that is appropriately protocolized.

5. In addition to informing the patient of the risks and benefits of surgical telementoring and accurately reflecting the scientific literature, the patient must be informed of the alternatives to the proposed new technology. In the case of telementoring, and depending on the patient, the only alternative will be in operation in a hospital with a surgical team with extensive experience in the proposed surgery, if the organizational structure permits this. In the case of acting surgeons, the alternative will be - if feasible - to acquire enough training to complete the learning curve so that the mentor is no longer required. In the case of the mentor, the alternative will be for their counseling to be be performed face-to-face in the operating room itself, if this is possible. Clearly, as with the rest of the informed consent, there are a number of situations that need to be considered: urgency, the patient's refusal to receive information, the patient's incapacity, treatments required by law (public health) and unforeseen circumstances during the operation.

\section{Analysis of the cost-effectiveness of the new technology}

New surgical procedures usually depend on new technology, which means an increase in expenses for the hospital. Direct, indirect and social costs must also be considered in the case of telemedicine, and therefore of surgical telementoring. The cost-effectiveness of telementoring is therefore an important factor to consider when approving its implementation. The literature contains numerous articles and reviews(41) that analyze the costs of telemedicine, but there are not enough studies or meta-analyses that demonstrate the savings involved in using telemedicine compared to conventional medicine. This problem is mainly due due to the lack of protocolized variables that enable these differences to be studied(42).

A cost-effectiveness analysis of telementoring is fundamental for assessing the ethical practice of 
this procedure. In specific terms, it involves respecting the ethical principle of justice, understood in terms of an effort that society makes to apply scientific advances for the good of society. Consequently, bearing in mind that the health economy always involves sacrifices when deciding between one technology and another, the opportunity cost of using telementoring compared to mentoring with the surgeon in the operating theater or other alternative equally effective solutions should be evaluated. There are no studies on either the cost-effectiveness of surgical telementoring or on the opportunity cost in the literature. These studies should assess the direct, indirect and social costs. However, it can be assumed that the social costs (travel, periods of leave from work, time of relatives or companions) and some direct health costs, such as operating times and hospital stays(43) will be lower with telementoring and, consequently, we can hypothesize that telementoring could be more cost-effective than the conventional method, while respecting the ethical principle of social justice.

\section{Global social solidarity}

Access to health services varies from one community to another and from one country to another. Beveridge-type national health systems - ensure that the entire population has access to the same levels of health technology. However, this is not always achieved. As a result, hospitals and medical centers in rural areas often have more limited access to the latest medical-surgical technologies. In this regard, telemedicine has provided a solution to protect this vulnerable population and thereby maintain the ethical value of social solidarity. With both telemedicine and surgical telementoring, geographical areas with less infrastructure can benefit from the latest innovations in health. This equitable distribution of healthcare is consistent with the ethical principle of justice and freedom, autonomy and authority of patients and institutions. However, if this is to be the case, it is necessary to confirm that telementoring is costeffective.

However, third world countries suffer from low investment in health and therefore prioritize the most essential technologies and treatments, with telemedicine left the background to provide care for remote areas or rural hospitals. Global solidarity should address these shortcomings and the applications of telemedicine, when they are costeffective, and would be a good tool for the universal redistribution of healthcare. Many projects are currently being undertaken in this field(44).

\section{Confidence of vulnerable patients}

Respecting the autonomy of the patient may mean that the patient, instead of being less passive and having patience, somehow becomes a more participatory agent, and an agent rather than a user. The danger with this concept of autonomy, which does not want to be patient, is that it is reluctant to accept important ethical values such as vulnerability, fragility and dependence. After all, in a context of budget cuts and worldwide demographic aging, respect for the autonomy of patients must involve creating a hierarchy of vulnerabilities.

When the decision is taken to operate on a patient using surgical telementoring, the principle of autonomy must be respected, but it must always be dependent on vulnerability and fragility. A good relationship between the surgeonmentor and operating surgeon and the patient is part of the respect for the patient's autonomy. In addition to listening to the patient's decisions, the patient must be accompanied, in a process defined by trust, in the consideration of alternatives, assessment of risks and benefits, and even relocating the disease in his life and thereby rearranging everything.

\section{The systematic approach. Existence of scientific evidence}

Although numerous studies have been published supporting the safety and efficacy of surgical telementoring, until recently there was not enough scientific evidence to indicate optimal use of the procedure. The studies published covered few patients or protocols and different technologies with different pathologies. The first systematic review in 2012(12) concluded that the surgical telementoring has an impact improving the education of surgeons with a complication rate similar to that of surgery without mentoring. The most important effort to provide scientific evidence 
came from the SAGES, which at a summit of experts of all professions related to telementoring in 2016(11), and after an exhaustive state of the art review of the new technology, concluded that the application of surgical telementoring is increasingly widespread, it is a safe technique but requires coordinated efforts by all those involved in the different health systems, which are not yet ready for the routine application of this new technology. All this means that we have a technology that has not yet been validated by public institutions.

From the ethical point of view, the challenge is to evaluate whether telementoring meets the requirements to be considered a technology with ethical guarantees(45): laboratory background, field strength, institutional stability and compulsory institutional review board evaluation. Surgical telementoring does not currently fully comply with these.

Consequently, from an ethical point of view, surgical telementoring still needs to resolve a range of issues that can be summarized as follows: monitoring by scientific societies and regulation by official national or supranational bodies, participation of medical ethics committees and the creation of databases from all the trials conducted and experience in hospitals where this new procedure has been applied to create sufficient information on its safety, efficacy and results. The Balliol Colaboration's IDEAL (innovation, development, exploration, assessment, and long-term study) model can be used as a template(46).

\section{Conflicts of interest}

In order to preserve the ethical principles of patient beneficence and non-maleficence, interactions between health professionals, industries, and institutions should seek the patient's interests by providing information on the best option for treating his or her illness.

Conflicts of interest in medical practice can be related to finance or prestige, and may affect doctors and the institutions where they work. The companies that develop the technology are also involved. These conflicts may impair the patient's appropriate therapeutic decision-making.
In the case of telementoring, in addition to the conflicts of interest mentioned above, we must add a third party related to the others, which is the educational aspect. In addition to providing the patient with additional safety when supervised by an expert, surgical telementoring is also a training tool for the operating surgeon enabling him to continue on the learning curve of the pathologies involved in the surgery. For the mentor, it is an opportunity to enhance his professional prestige. Educational conflicts of interest in surgical telementoring will arise if the operating surgeons only seek an opportunity to make progress in their training rather than the benefit and non-maleficence of their patients' health. Similarly, there will be conflict of interests if the mentor exclusively prioritizes his prestige to the detriment of the interests of the patient. This dilemma can be resolved by supervision by the ethical committee of the health care center when surgical telementoring is proposed to their patients.

\section{Conclusions}

Surgical telementoring allows real information to be shared online between an experienced mentor surgeon and operating surgeons in the operating room, who are in different geographic locations, using ICT. The goal of this new technology is to provide education for surgeons and to improve patient care. The most important beneficiaries of this technology are health centers in rural and remote areas and hospitals on the battlefield, where it is almost impossible to obtain expert care for some operations and pathologies.

The world's increasing globalization and the development of ICT have enabled this technology to develop rapidly in recent years. Many studies have corroborated its reliability, efficiency and cost-effectiveness and suggest that telementoring is safe and achievable. It is possible that in the future it will be adopted as a service at more health centers, due to the demand among professionals. For all these reasons, and because it offers certain advantages for both patients and the surgeons, it is necessary to consider the ethical aspects to validate its use in medical practice.

The ethical challenges and dilemmas of surgical telementoring identified and analyzed in this pa- 
per cover multiple aspects, such as patient safety, privacy and vulnerability, the surgeon-mentorpatient relationship and informed consent, professional responsibility, a cost-effectiveness analysis and solidarity and social justice regarding the use of healthcare resources, a systematic approach to the validation of the proposed new technology and conflicts of interest.

When implementing a surgical innovation, concern for patient safety should be the first need to be addressed, and safety in telementoring includes the safety of ICT for the exchange of live information, safery in personal interrelationships and the degree of training of the surgeons (the mentor and operating surgeons) for undertaking telementoring, and the safety of the experience of surgeons in the pathology to be operated on.

Surgical telementoring establishes a new mentorpatient relationship that should be part of a new three-way relationship with the operating surgeons. Meanwhile, there is a dimension involved in the determination of professional responsibility towards the mentor within the surgical team; this responsibility can only be required of the mentor due to the competences that have been assigned to him as part of the role defined for him in the pre, intra and postoperative periods.
This new technology needs a new informed consent in which the mentor figure appears. In addition, the principle of therapeutic privilege should be avoided, and the patient should have the opportunity to be informed of the risks with their complications, benefits and alternatives of surgical telementoring. When it is a surgical innovation, offering the patient biased information should be avoided, to ensure that the patient does not take the decision without adequately assessing the new technique offered. The principle of autonomy must be maintained, while always taking into account vulnerability and fragility.

There is no scientific evidence to conclude that surgical telementoring is more cost-effective than traditional surgery, but due to its shorter surgery time and shorter hospital stays, the use of mentoring is anticipated to be more economical. It is important that this telemedicine system can be used to bring surgical experience closer to areas with the most disadvantaged population groups.

Once these issues have been identified and resolved, it is necessary to subsequently establish a regulation - also in the legal field - governing the use of surgical telementoring, which should be the responsibility of public health institutions and professional societies. This will enable surgical telementoring to be reliably adapted to each specific case. 


\section{References}

1. McCullogh LB, Jones JW. The art of medicine: unraveling ethical challenges in surgery. Lancet, 2009; 374(9695): 1058-1059.

2. Little M. The fivefold root of an ethics of surgery. Bioethics 2002; 16(3): 183-201.

3. Angelos P. The ethical challenges of surgical innovation for patient care. Lancet 2010; 376(9746): 1046-1047.

4. Stanberry B. Telemedicine: Barriers and opportunities in the 21st century. J Int Med 2000; 247(6): 615-628.

5. Kvedar J, Coye MJ, Everett W. Connected health: a review of technologies and strategies to improve patient care with telemedicine and telehealth. Health Aff (Millwood) 2014; 33(2): 194-199.

6. Wootton R, Bonnardot L. In what circumstances is telemedicine appropriate in the developing world? JRSM Short Rep. 2010; 1(5): 37.

7. Society of American Gastrointestinal Endoscopic Surgeons (SAGES). Guidelines for the surgical practice of telemedicine. Surg Endosc. 2000; 14: 975-979.

8. Schlachta CM, Kent SA, Lefebvre KL, McCune ML, Jayaraman S. A model for longitudinal mentoring and telementoring of laparoscopic colon surgery. Surg Endosc. 2009; 23(7): 1634-1638.

9. Ballantyne GH. Robotic surgery, telerobotic surgery, telepresence, and telementoring. Surg Endosc. 2002; 16(10): 13891402.

10. Lenihan J, Brower M. Eb-connected surgery: using the internet for teaching and proctoring of live robotic surgeries. $J$ Robot Surg. 2011; 6(1): 47-52.

11. Schlachta CM, Nguyen NT, Ponsky T, Dunkin B. Project 6 Summit: SAGES telementoring initiative. Surg Endosc. 2016; 30(9): 3665-3672.

12. Antoniou SA, Antoniou GA, Franzen J, Bollmann S, Koch OO, Pointner R, Granderath FA. A comprehensive review of telementoring applications in laparoscopic general surgery. Surg Endosc. 2012; 26(8): 2111-2116.

13. Ponsky TA, Schwachter M, Parry J, Rothenberg S, Augestad KM. Telementoring: the surgical tool of the future. Eur J Pediatr Surg. 2014; 24(4): 287-294.

14. Fuertes-Guiró F, Vitali-Erion E, Rodriguez-Franco A. A program of telementoring in laparoscopic bariatric surgery. Minim Invasive Ther Allied Technol. 2016; 25(1): 8-14.

15. Santomauro M, Reina GA, Stroup SP, L'Esperance JO. Telementoring in robotic surgery. Curr Opin Urol. 2013; 23(2): 141-145.

16. El-Sabawi B, Magee W. 3rd. The evolution of surgical telementoring: current applications and future directions. Ann Transl Med. 2016; 4(20): 391.

17. Augestad KM, Chomutare T, Bellika JG, Budrionis A, Lindsetmo RO, Delaney CP, Mobile Medical Mentor (M3) Project Group. Surgical telementoring in knowledge translation-clinical outcomes and educational benefits: a comprehensive review. Surg Innov. 2013; 20(3): 273-281.

18. Anvari M, McKinley C, Stein H. Establishment of the world's first telerobotic remote surgical service: for provision of advanced laparoscopic surgery in a rural community. Ann Surg. 2005; 241(3): 460-464.

19. Mistry H. Systematic review of studies of the cost-effectiveness of telemedicine and telecare. Changes in the economic evidence over twenty years. J Telemed Telecare 2012; 18(1): 1-6.

20. Silverman RD. Current legal and ethical concerns in telemedicine and e-medicine. J Telemed Telecare 2003; 9 Suppl 1: S67-9.

21. Fleming DA, Edison KE, Pak H. Telehealth ethics. Telemed J E Health. 2009; 15(8): 797-803.

22. Ethical guidelines in telemedicine. Available from http://doc.cpme.eu:591/adopted/cp\%201997_033.pdf Revised on 12/1/2017

23. World Medical Associations. Available from http://www.wma.net/en/30publications/10policies/t3/ Revised on 12/1/2017

24. Farouk A. Telemedicine prompts new ethical ground rules for physicians. AMA Wire, Jun 13, 2016. Available from https://wire.ama-assn.org/ama-news/telemedicine-prompts-new-ethical-ground-rules-physicians Revised on 12/1/2017

25. The National Commission for the Protection of Human Subjects of Biomedical and Behavioral Research. The Belmont Report. Ethical Principles and Guidelines for the Protection of Human Subjects of Research. Appendix Vol. II. Available from https://videocast.nih.gov/pdf/ohrp_appendix_belmont_report_vol_2.pdf Revised on 12/1/2017

26. Fuertes-Guiró F, Viteri Velasco E. Ethical issues in surgical telementoring: challenges and dilemmas of an innovative technology. Minerva Chir. 2018 Feb 1 [Epub ahead of print]. 
27. Sebajang H, Trudeau P, Dougall A, Hegge S, McKinley C, Anvari M. Telementoring: an important enabling tool for the community surgeon. Surg Innov. 2005; 12(4): 327-331.

28. Budrionis A, Hartvigsen G, Lindsetmo RO, Bellika JG. What device should be used for telementoring? Randomized controlled trial. Int J Med Inform. 2015; 84(9): 715-723.

29. Augestad KM, Bellika JG, Budrionis A, Chomutare T, Lindsetmo RO, Patel H, Delaney C. Mobile Medical Mentor (M3) Project. Surgical telementoring in knowledge translation--clinical outcomes and educational benefits: a comprehensive review. Surg Innov. 2013; 20(3): 273-281.

30. Bogen EM, Augestad KM, Patel HR, Lindsetmo RO. Telementoring in education of laparoscopic surgeons: An emerging technology. World J Gastrointest Endosc. 2014; 6(5): 148-155.

31. Birch DW, Asiri AH, De Gara CJ. The impact of a formal mentoring program for minimally invasive surgery on surgeon practice and patient outcomes. Am J Surg. 2007; 193(5): 589-591.

32. Rosser JC Jr, Young SM, Klonsky J. Telementoring: an application whose time has come. Surg Endosc. 2007; 21(8): 1458-1463.

33. Challacombe B, Kavoussi L, Patriciu A, Stoianovici D, Dasgupta P. Technology insight: telementoring and telesurgery in urology. Nat Clin Pract Urol. 2006; 3(11): 611-617.

34. Latifi R, Peck K, Satava R, Anvari M. Telepresence and telementoring in surgery. Stud Health Technol Inform. 2004; 104: 200-206.

35. Kon AA, Walter RJ. Health Care Ethics Consultation via Telemedicine: Linking Expert Clinical Ethicists and Local Consultants. AMA J Ethics 2016; 18(5): 514-520.

36. St Julien J, Perrier ND. Video Telementoring to Accelerate Learning of New Surgical Techniques. JAMA Surg. 2016; 151(7): 671-672.

37. Budrionis A, Hasvold P, Hartvigsen G, Bellika JG. Assessing the impact of telestration on surgical telementoring: A randomized controlled trial. J Telemed Telecare 2016; 22(1): 12.

38. Eadie LH, Seifalian AM, Davidson BR. Telemedicine in surgery. Br J Surg. 2003; 90(6): 647-658.

39. Glenn IC, Bruns NE, Hayek D, Hughes T, Ponsky TA. Rural surgeons would embrace surgical telementoring for help with difficult cases and acquisition of new skills. Surg Endosc. $2016 \mathrm{Jul}$ 21. [Epub ahead of print].

40. Angelos P. Ethics and surgical innovation: challenges to the professionalism of surgeons. J Surg. 2013; 11 Suppl 1: S2-5.

41. Akiyama M, Yoo BK. A Systematic Review of the Economic Evaluation of Telemedicine in Japan. J Prev Med Public Health 2016; 49(4): 183-196.

42. Fritz F, Kebede M, Tilahun B. The need for cost-benefit analyses of eHealth in low and middle-income countries. Stud Health Technol Inform. 2015; 216: 991.

43. Wood D. No surgeon should operate alone: how telementoring could change operations. Telemed J E Health 2011; 17(3): 150-152.

44. Forgione A, Kislov V, Guraya SY, Kasakevich E, Pugliese R. Safe introduction of laparoscopic colorectal surgery even in remote areas of the world: the value of a comprehensive telementoring training program. J Laparoendosc Adv Surg Tech A. 2015; 25(1): 37-42.

45. Johnson J, Rogers W. Innovative surgery: the ethical challenges. J Med Ethics 2012; 38(1): 9-12.

46. Pennell CP, Hirst AD, Campbell WB, Sood A, Agha RA, Barkun JS, McCulloch P. Practical guide to the Idea, Development and Exploration stages of the IDEAL Framework and Recommendations. Br J Surg. 2016; 103(5): 607-615.

Received: February 19, 2018

Accepted: March 14, 2019 